\title{
Impact of Team Work on Employee Satisfaction
}

\author{
Sobia Shujaat \\ Bahria University, Karachi \\ Amir Manzoor \\ Bahria University, Karachi \\ Nadeem A. Syed \\ SZABIST, Karachi
}

\begin{abstract}
Purpose: The current study was based on analyzing effect of team work on employee satisfaction, as team work is considered to be a crucial factor for achieving organizational goals.

Methodology/Sampling: A survey was conducted among 384 employees from different organization to analyze their team work experience. Regression analysis was applied to access the significance of linear relationship on data under study.

Findings: It was found that team work has a significant impact on employee satisfaction. Future research should investigate the ways in which teamwork interest can be moderated by characteristics of the task and the group, preferably those characteristics that instructors have some control over to facilitate group work experiences.

Practical Implications: Employers value team work skills from incoming employees with higher education. Hence it is critical that instructors in higher education institutions understand the importance of teamwork and the factors that contribute to positive teamwork environment. The study will be helpful for HR departments to understand the importance of team work and for devising better work groups.
\end{abstract}

Keywords: Workplace, Satisfaction, Productivity.

JEL Classification: M190, M140

\footnotetext{
* The material presented by the authors does not necessarily portray the viewpoint of the editors and the management of the Institute of Business \& Technology (IBT).

* Sobia Shujaat: sobiashujaat@bimcs.edu.pk

* Amir Manzoor: amirmanzoor@bimcs.edu.pk

* Nadeem A. Syed: drnadeemsyed@gmail.com

CJMSS is published by the Institute of Business and Technology (IBT). Main Ibrahim Hydri Road, Korangi Creek, Karachi-75190, Pakistan.
} 


\section{INTRODUCTION}

It is observed that those employees who work in groups or teams instead of the conventional based workplace have higher satisfaction. Employees are being trained in teams to achieve their targets related to their job (Erdem et al. 2003). Work team refers to a group of individuals who work interdependently to solve problems or carry out tasks (Keller, 2001). Deming implies that a high degree of employee teamwork is vital to organizational performance and for the achievement of quality and productivity improvement (Costa, 2003). There can be various techniques and approaches to satisfy employees at workplace; including practices related to work environment, organizational culture, encompassing trust based relationship, problem solving and cooperation among employees within various departments (Keller, 2001). In fact employee satisfaction deals with the quality of life and workplace in order to enhance workers' performance and motivation level. (Furumo et al. 2009).

Teamwork is defined as "a work group with a common purpose through which members develop mutual relationships for the achievement of goals/ tasks" (Harris and Harris, 1996). For the group to succeed, individuals need to collaborate effectively with each other. Peer collaboration in academic contexts has numerous potential benefits including increased achievement, improved problem solving, increased self-esteem, favorable learning attitudes, and satisfaction (Burdett and Hastie, 2009; Colbeck et al., 2000; Goldfinch and Hughes, 2007). Teamwork is seen as critical for today's workforce (Stevens and Campion, 1994), and employers value teamwork skills from incoming employees of higher education programs (Chen et al., 2004). Increased satisfaction is linked to employee engagement and selfperceptions of learning (Brown, 2010; Howell, 2006). Chen (2004) examined the relationship between skill-development strategies and group work satisfaction among undergraduate employees. The results indicates that group members are more satisfied with their learning outcomes when the group is engaged in skills such as conflict management and defining group roles and processes (Scotter, 2000). Employees' job satisfactions and level of participation in work teams determines the overall performance of a team in particular and an organization as a whole. Therefore, the current research aims to find the effect of team work on employee job satisfaction.

\subsection{Hypothesis}

A corresponding hypothesis was formulated to analyze the effect of team work on employee satisfaction.

$\mathrm{H}_{1}$ : There is a significant effect of teamwork on an employee job satisfaction

\subsection{Research Limitations}

There are some limitations that should be considered when interpreting the results.

- A sample of 384 respondents is taken for this research due to unavailability of resources, which might not be a true reflection of the entire population.

- The tested models had relatively few statistical parameters, which decrease the stability of the results. 
- The results are also limited as the data had some missing data points, limiting the sample size, power of the analyses, and potentially, accuracy of the aggregated variables.

- Only a handful of studies have examined teamwork interest despite its relationship to individual characteristics and outcomes of interest for group work such as emotional intelligence, team participation, team performance, and team cohesion.

\section{LITERATURE REVIEW}

Rewarding individual employees can produce negative outcomes by eroding workplace cohesion, as employees become reluctant to share information with others even at the expense of reduced output. Furumo, Pillis \& Green (2009) cited in their research "Personality influences trust differently in virtual and face-to-face teams" Relative comparisons at the individual level create competition which results in decreased trust, sharing and teamwork. Kline (2001) defined a work team as a group within an organization, which is established and maintained in order to complete a common task, and where members are collectively responsible for the task. When employees work towards a common task they become interdependent on each other. Hunter et al. (2010) found team resources based on critical social resources at work that help individuals to grow and develop were positively related to work-family enrichment and project satisfaction. Ultimately, team conflict can influence performance. When team members experience conflict they often choose to compete with each other, leading to less team efficacy, but also higher feelings of distrust and negative emotions. Team task conflict is negatively related to team member satisfaction (Kottke, 2008).

A useful way to understand various types of teams is the concept of organizational shell, first used by Kearney et.al, (2009) to describe how an organization provides a structural context for the functioning of a team. The level of trust within a group is constantly changing according to group members' willingness to be trustworthy. Scotter (2000) assured that the developmental views of trust are closely intertwined with the process of relationship development. As there is often little time for relationship building in virtual teams, team members are presumed to trust others based on their past experiences or from other settings with which they are familiar (Brown et al. 2006; Costa et al., 2001; Kearney et.al, 2009). As soon as the team begins to interact, positive experiences regarding the behavior and assumed intentions of team members can improve trust.

Teamwork satisfaction can be defined as "a positive affective response that members have to some element pertaining to a small group" (Kearney et.al, 2009). Costa et al. (2001) have cited measures of satisfaction as dimensions of effectiveness on learning performance predicted by trust. The study suggested that trust is positively related to team satisfaction, task performance, and relationship commitment, and negatively related to stress. Furthermore, Costa et.al, (2001) advocated that building relationships and establishing trust among team members is essential to team satisfaction. In teams, communication is critical in providing, assessing, and synthesizing team members' inputs. If members do not communicate, the unique ideas of each member will not be shared. According to Marks (2001) communication is necessary for several teamwork dynamics including strategy formulation and planning, systems monitoring, coordination, motivation, confidence building, and affect management. Agreeable members of a team encourage others to contribute, support each other's unique perspectives, and help establish a safe environment for the sharing of information (Graziano et al., 1996). As 
information and ideas are shared, agreeable team members are more likely to promote constructive criticism in ways that allow for more effective decision-making processes.

Mohammed and Angell (2004) found team orientation had no direct impact on group work outcomes, but did interact with other aspects of the team, specifically diversity, to predict group work performance. Furthermore, research indicates that teamwork interest is correlated with extraversion (Ilarda and Findlay, 2006). It also signifies that the impact of teamwork interest is dependent on alternative team characteristics, including personality.

Future research should further investigate the ways in which teamwork interest can be affected by characteristics of the task and the group, preferably characteristics that instructors have some control over to facilitate group work experiences. Literature shows that teamwork interest is simply a better predictor of performance than satisfaction. Again, future research is needed to warrant this assertion. The extraversion dispersion results are also surprising, particularly because they are inconsistent with much of the literature, suggesting greater mean extraversion predicts better performance and greater satisfaction (Barrick et al., 1998; Humphrey et al., 2011; Peeters et al., 2006a). However, most of the results on group extraversion focus on predicting performance rather than satisfaction (Peeters et al., 2006a). Future studies should focus on group work satisfaction as an outcome for group personality, with the intention of improving group work facilitation.

Teamwork interest has been found to correlate to team cohesion in earlier studies; it still might be useful to use such an instrument of teamwork interest to help compose groups. Also, extroversion may be useful to compose groups. More specifically, instructors may want to use pre-project surveys to identify individual personalities, and compose groups of students who are alike in extroversion to promote a positive group experience. Extraversion may trump teamwork interest, at least in academic-focused project groups. More importantly, the results have implications for instructors who want to improve the group work experiences of their students. With respect to extraversion, individuals of homogenous groups appear to be more satisfied with their group experience. Group work is an increasingly vital tool for instruction with several known benefits including the ability to improve the learning experience, selfesteem, and achievement and to strengthen knowledge, skills, and problem solving abilities (Hillyard et al., 2010; Chen, 2004). The study can also be helpful for universities as it can lay the groundwork for the students' skill development needed today in team-oriented workforce.

\section{RESEARCH METHODOLOGY}

The research is quantitative in nature. Quantitative research describes behavior in the form of models, correlations, and numerical forms as accurately as possible and makes it predictable (Fossey et.al, 2002).

This research is based upon the in-depth study and relies on on primary data which included the filling of questionnaires from employees of several banks operating in Karachi. The data was self-monitored and collected personally. It took two weeks to visit and collect data from different offices. The sampling technique which was utilized to collect the data from the respondents was "convenience sampling". The purpose for selecting this technique was that the author was limited with the number of respondents by the Human Resource 
departments of various banks. The sample was selected from the employees working in banks operating in Karachi. 384 respondents were approached from different banks operating in Karachi including Habib Bank Ltd, Muslim Commercial Bank, Union Bank Ltd, National Bank of Pakistan and Allied Bank Ltd. Questionnaires were filled out by the selected respondents. The questionnaire was formulated on five-point likert scale including options; strongly agree, agree, neutral, disagree, and strongly disagree. For the analysis of the research data, regression analysis was used in this study. Another frequently used measure is the arithmetic mean, which reflects the average level of the phenomenon.

\section{Findings and Interpretation of the Results}

Table 4.1: Regression Model

Model Summary

\begin{tabular}{|c|c|c|c|c|}
\hline Model & $\mathrm{R}$ & R Square & Adjusted R Square & Std. Error of the Estimate \\
\hline 1 & $.365^{\mathrm{a}}$ & .133 & .127 & 1.181 \\
\hline
\end{tabular}

a. Predictors: (Constant), I think that productivity of work improves in group work or teams?, I have the opportunity to develop my skills while working in a team?, I am satisfied with the way I can take part in the decision making of the group

ANOVA $^{b}$

\begin{tabular}{|ll|l|l|l|l|l|}
\hline Model & & Sum of Squares & Df & Mean Square & F & Sig. \\
\hline 1 & Regression & 81.617 & 3 & 27.206 & 19.506 & $.000^{\mathrm{a}}$ \\
& Residual & 530.008 & 380 & 1.395 & & \\
& Total & 611.625 & 383 & & & \\
\hline
\end{tabular}

a. Predictors: (Constant), I think that productivity of work improves in group work or teams?, I have the opportunity to develop my skills while working in a team?, I am satisfied with the way I can take part in the decision making of the group

b. Dependent Variable: I am generally satisfied with a team-based way of working.

\section{Coefficients $^{\mathrm{a}}$}

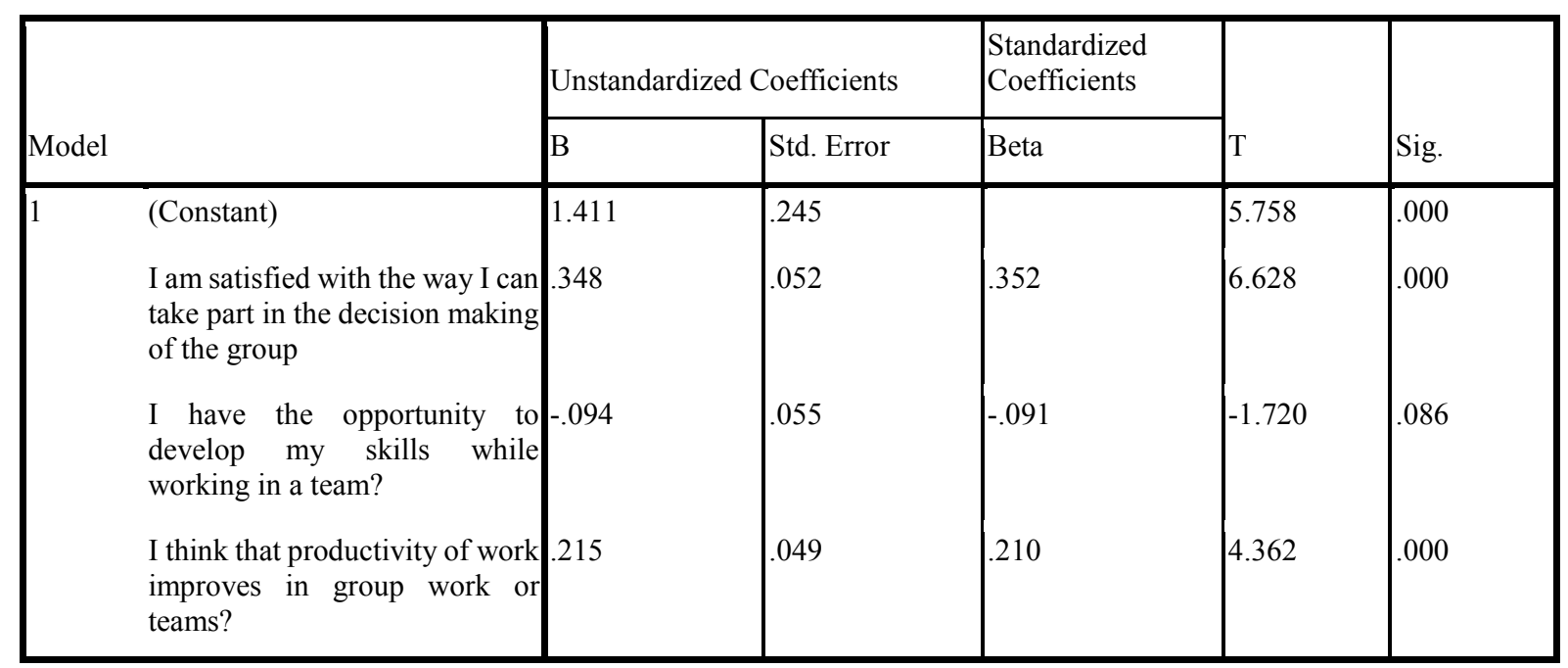

a. Dependent Variable: I am generally satisfied with a team-based way of working. 
In Table 4.1 the multiple regression test have been applied on the study variables. The regression analysis is an appropriate statistical technique for finding the linear relationship between variables. In the above model there are three different tables for explanation of results.

In the first table of model summary, the value of $\mathrm{R}$ (Multiple correlation coefficient) explains the relationship between the regression model and dependent variable. In above results it represents $36.5 \%$ reliability of model on dependent variable. In the ANOVA table (Analysis of Variance) the significance of regression model is tabulated. The regression test have been applied on $95 \%$ confidence level, therefore for the validity of regression test the sig-value of the ANOVA table should be less than 5\% level of significance i.e. (less than 0.05). It can be seen in the last column of ANOVA table that the value is significant at 0.000 .

Therefore, the regression model is valid and significant. In the last table of coefficients, the hypothesis results are based. In this table independent variables are present with their beta and sig values; beta values predict the degree of relationship with the dependent variable while sigvalues represent the significance of relationship. It is evident that sig-value of employee satisfaction and productivity is significant at 5\% level of significance. Null hypothesis is accepted as there is a significant effect of dependent variable of independent variables.

Table 4.2: Frequency Distribution

I am satisfied with the way I can take part in the decision making of the group

\begin{tabular}{|ll|l|l|l|l|}
\hline & Frequency & Percent & Valid Percent & Cumulative Percent \\
\hline Valid & Strongly Agree & 68 & 17.7 & 17.7 & 17.7 \\
Agree & 91 & 23.7 & 23.7 & 41.4 \\
Neutral & 93 & 24.2 & 24.2 & 65.6 \\
Disagree & 86 & 22.4 & 22.4 & 88.0 \\
Strongly Disagree & 46 & 12.0 & 12.0 & 100.0 \\
Total & 384 & 100.0 & 100.0 & \\
\hline
\end{tabular}

I have the opportunity to develop my skills while working in a team?

\begin{tabular}{|ll|l|l|l|l|}
\hline & Frequency & Percent & Valid Percent & Cumulative Percent \\
\hline Valid & Strongly Agree & 34 & 8.9 & 8.9 & 8.9 \\
Agree & 91 & 23.7 & 23.7 & 32.6 \\
Neutral & 67 & 17.4 & 17.4 & 50.0 \\
Disagree & 133 & 34.6 & 34.6 & 84.6 \\
Strongly Disagree & 59 & 15.4 & 15.4 & 100.0 \\
Total & 384 & 100.0 & 100.0 & \\
\hline
\end{tabular}

The above frequency distribution tables elaborate the level of agreement and responses by the respondents. The first frequency table shows that cumulative percentage is $41.1 \%$ 
intimating that employees are satisfied with the way they can take part in the decision making of the group, $24.2 \%$ neutral while rest $34.2 \%$ are not satisfied.

Figure 4.1: Pie Chart

I am satisfied with the way I can take part in the decision making of the group
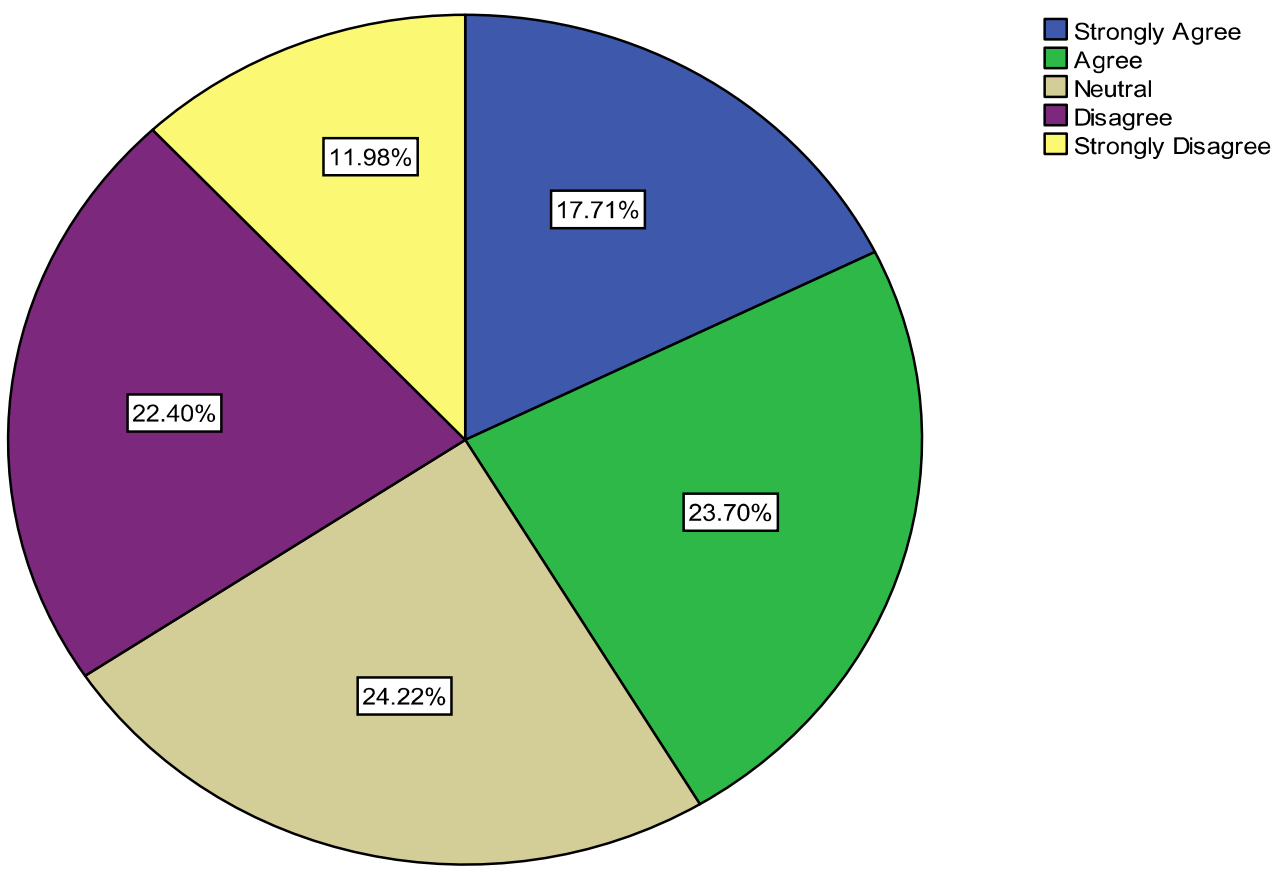

Figure 4.2: Pie Chart

I have the opportunity to develop my skills while working in a team?

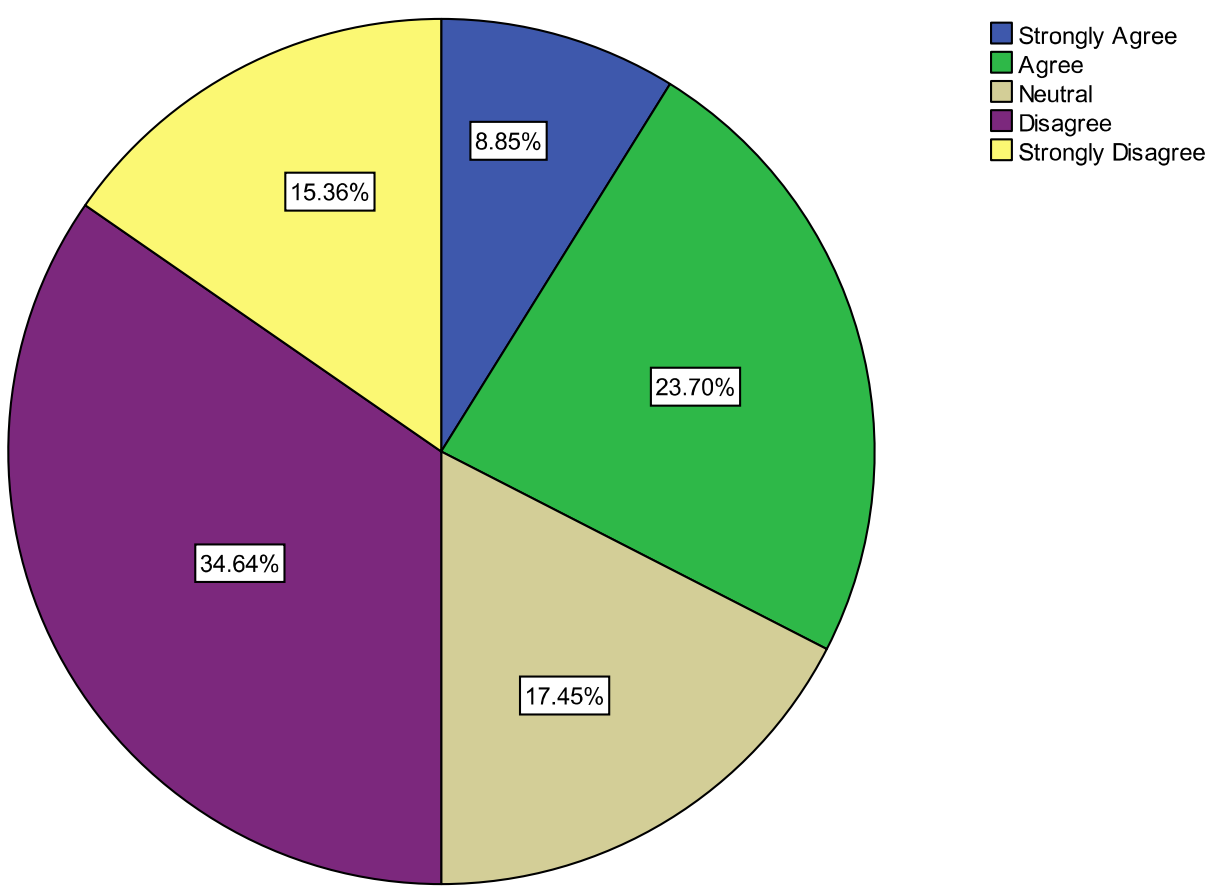


The above pi-charts are the graphical presentation of the frequency distribution table. Results are self-explanatory.

\section{DISCUSSION \& CONCLUSION}

The current thesis was based on analyzing impact of team work on employee satisfaction. Satisfaction of employees at work is necessary to strengthen them psychologically which can ultimately create impact on individual performance and thus satisfaction can be achieved. Team work is the essence of a work place; team work is required at every step of achieving certain organizational goals and objectives. Therefore, employee satisfaction is an essential element of the team members working together for the accomplishment of organizational goals. In the study, it was found that team work has positive significant impact on employee satisfaction and employees' productivity. The results were significant indicating linear relationship between the variables under study. Furthermore, building on the findings of Leiter (1988), results support that better team communication may also spill-over beyond the workplace, leaving employees more satisfied with life.

The results further support the findings of Iverson \& Maguire, 2000 that teams-based factors could overflow beyond the workplace and influence an employee's overall satisfaction with the job and organization. After all, teams need an adequate level of work satisfaction to function, but too much work pressure may stifle creative processes and hinder performance. Regarding individual employee performance in a team, future research should replicate the current findings with other measures of performance standards.

Future research can analyze more factors that may influence team work and employee satisfaction. In addition, future research should explore the conditions when teamwork improves or hinders the communication of ideas and satisfaction of members. It may be that a linear relationship between willingness to work in a team on one hand and idea communication and performance and job satisfaction on the other explains this difference. In addition, by responding to calls for non-workplace outcomes to be tested (Chung-Yan \& Moeller, 2010) including at the multi-level (Jones et al., 2004), studies found support for team-based factors influencing individual-level life satisfaction. Teams that reported higher levels of task conflict was found to be negatively linked to life satisfaction, while conversely, teams that reported greater communication were positively related.

\section{RECOMMENDATIONS}

As teams can enhance the overall performance of employees, organizations are supposed to design teams keeping in view the characteristics that effect teams output positively. Universities should prepare students to work in teams as it is a requirement in the corporate world today. For team performance, better communication are removal of task conflict and are important, this would result in employee satisfaction.

\section{REFERENCES}


An, H., \& Kim, S. (2007). The perceived benefits and difficulties of online group work in a teacher education program. International Journal of Instructional Technology and Distance Learning, 4(5), 3-20.

Barrick MR, Stewart GL, Neubert MJ, et al. (1998) Relating member ability and personality to work-team processes and team effectiveness. Journal of Applied Psychology 83: 377-91.

Bonwell C and Eison J (1991) Active Learning: Creating Excitement in the Classroom AEHE-ERIC Higher Education Report No. 1. Washington, DC: Jossey-Bass.

Brown PJ (2010) Process-oriented guided-inquiry learning in an introductory anatomy and physiology course with a diverse student population. Advances in Physiological Education 34: $150-5$.

Brown, L. A., Eastham, N. P., \& Ku, H. Y. (2006). A performance evaluation of the collaborative efforts in an online group research project. Performance Improvement Quarterly, 19(3), 121140.

Burdett J and Hastie B (2009) Predicting satisfaction with group work assignments. Journal of University Teaching and Learning Practice 6: 61-71.

Chen G, Donahue L and Klimoski R (2004) Training undergraduates to work in organizational teams. Academy of Management Learning \& Education 3: 27-40.

Colbeck CL, Campbell SE and Bjorklund SA (2000) Grouping in the dark: What college students learn from group projects. Journal of Higher Education 71: 60-83.

Costa PT and McCrae RR (1992) Normal personality assessment in clinical practice: The NEO personality inventory. Psychological Assessment 4: 5-13.

Costa, A. C. (2003). Work team trust and effectiveness. Personnel Review, 32(5), 605-623.

Costa, A. C., Roe, R. A., \& Taillieu, T. C. B. (2001). Trust implications for performance and effectiveness. European Journal of Work \& Organizational Psychology, 10(3), 225-244.

Furumo, K., Pillis, E., \& Green, D. (2009). Personality influences trust differently in virtual and face-to-face teams. International Journal of Human Resources Development and Management, 9(1), 36-58.

Goldberg LR (1992) The development of markers for the Big-Five factor structure. Psychological Assessment 4: 26-42.

Goldfinch J and Hughes M (2007) Skills, Learning Styles and Success of First-Year Undergraduates. Active Learning in Higher Education 8: 259.

Hackman JR and Oldham GR (1976) Motivation Through the Design of Work: Test of a Theory. Organizational Behavior and Human Performance 16: 250-279.

Harris PR and Harris KG (1996) Managing effectively through teams. Team Performance Management 2: 23-66.

Hillyard C, Gillespie D and Littig P (2010) University students' attitudes about learning in small groups after frequent participation. Active Learning in Higher Education 11: 9-20.

Howell CL (2006) Student Perceptions of Learner-Centered Education. Paper presented at the Annual Conference of the Northern Rocky Mountain Educational Research (ERIC Reproduction Series: ED494914).

Humphrey SE, Hollenbeck JR, Meyer CJ, et al. (2011) Personality configurations in self-managed teams: A natural experiment on the effects of maximizing and minimizing variance in traits. Journal of Applied Social Psychology 41: 1701-32. 
Kearney, Eric, Gebert, Diether, Voelpel, Sven C. (2009). "When and How Diversity Benefits Teams: The Importance of Team Members' Need for Cognition," Academy of Management Journal, 52(3), p581-598.

Keller, R. T. (2001). Cross-functional project groups in research and new product development: Diversity, communications, job stress, and outcomes. Academy of Management Journal, 44, 547-555.

Kline TJB (1999) The team player inventory: Reliability and validity of a measure of predisposition toward organizational team-working environments. The Journal for Specialists in Group Work 24: $102-12$.

Kottke JL (2008) Able but not willing? Teamwork aptitude and interest meet head-on. In: Presented at the annual conference of the society for industrial and organizational psychology, San Diego, CA, 10 April.

Scotter, J.R.V. (2000). Relationships of Task Performance and Contextual Performance With Turnover, Job Satisfaction, and Affective Commitment. Human Resource Management Review, Vol 10, No. I, pp. 76-95. 